\title{
Multiresponsive Polymer Nanoparticles Based on Disulfide Bonds
}

Maximilian Wagner ${ }^{1}$, Anja Krieger ${ }^{1}$, Benjamin Hämisch², Martin Minameyer ${ }^{3}$, Thomas Drewello ${ }^{3}$, Klaus Huber ${ }^{2}$ and Franziska Gröhn*,1

\section{Supporting Information}

\footnotetext{
${ }^{1}$ Department of Chemistry and Pharmacy \& Interdisciplinary Center for Molecular Materials (ICMM) and Bavarian Polymer Institute (BPI), Friedrich-Alexander University (FAU) Erlangen-Nürnberg, Egerlandstraße 3, 91058 Erlangen,

2 Physical Chemistry, Department of Chemistry, University of Paderborn, Warburger Straße 100, 33098 Paderborn, Germany

${ }^{3}$ Physical Chemistry I, Department of Chemistry and Pharmacy, Friedrich-Alexander University (FAU) Erlangen-Nürnberg, Egerlandstraße 3, 91058 Erlangen, Germany
} 
Table S1. Concentrations related to the PETMP to ionic thiol ratios at a constant $\mathrm{c}(\mathrm{R}-\mathrm{SH})=1 \mathrm{mmol} \mathrm{L}^{-1}$.

\begin{tabular}{ccl}
\hline $\begin{array}{c}\text { Ratio } \\
\text { PETMP:ionic } \\
\text { thiol }\end{array}$ & $\begin{array}{c}\text { PETMP } \\
/ \mathrm{mol} \mathrm{L}^{-1}\end{array}$ & $\begin{array}{c}\text { MPA,MSA,AET } \\
/ \mathrm{mol} \mathrm{L}^{-1}\end{array}$ \\
\hline $2: 1$ & $1.67 \times 10^{-4}$ & $3.33 \times 10^{-4}$ \\
$1: 1$ & $1.25 \times 10^{-4}$ & $5.00 \times 10^{-4}$ \\
$1: 2$ & $8.83 \times 10^{-5}$ & $6.67 \times 10^{-4}$ \\
$1: 8$ & $2.78 \times 10^{-5}$ & $8.89 \times 10^{-4}$ \\
\hline
\end{tabular}
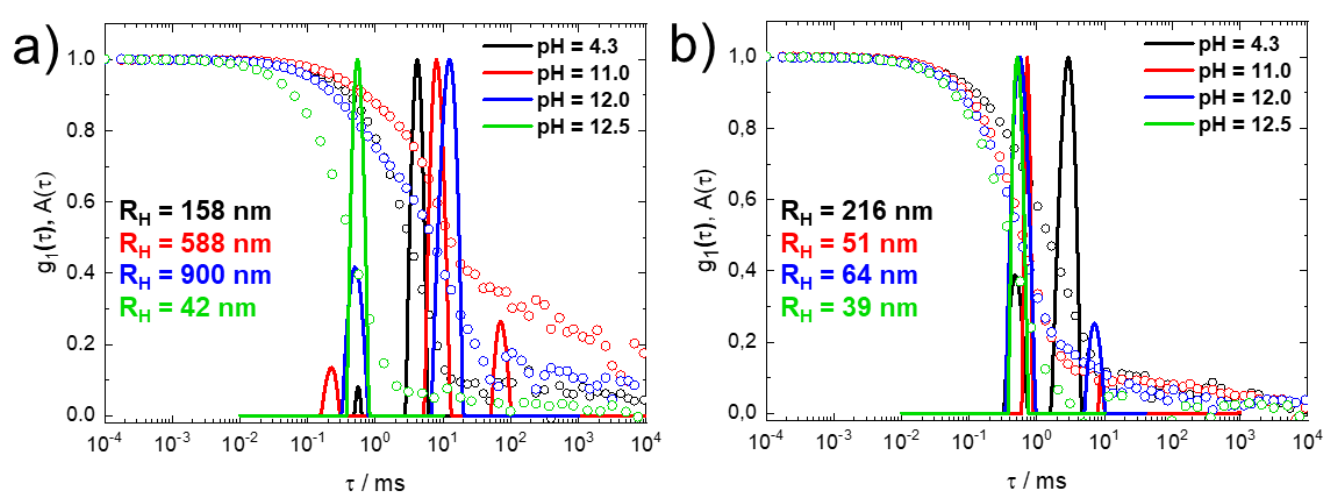

Figure S1. Dynamic light scattering of disulfide polymers in dependence on varying $\mathrm{pH}$ : Autocorrelation function of the electric field $\mathrm{g}_{1}(\mathrm{~T})$ (circles) and distribution function of relaxation times $\mathrm{A}(\mathrm{T})$ (lines) of polyMSA 2:1 (at a scattering angle $\theta=90^{\circ}$ ). Hydrodynamic radii given result from the angular dependent analysis.<smiles>O=C(O)CCS</smiles>

MPA<smiles>[2H]C(CCS)C(=O)OCC(CCl)(COC(=O)CCS)COC(=O)CCS</smiles>

PETMP<smiles>[2H]C(CCSSCC)SSCCC(=O)OCC(C)(COC(=O)CCSSCCC(=O)O)COC(=O)CCSSCCC(=O)O</smiles>

polyMPA 2:1

Figure S2. Spectra assignment of MPA, PETMP and polyMPA in 1H-NMR depicted in Figure 6. 
<smiles>O=C(O)C(S)C(=O)O</smiles>

MSA

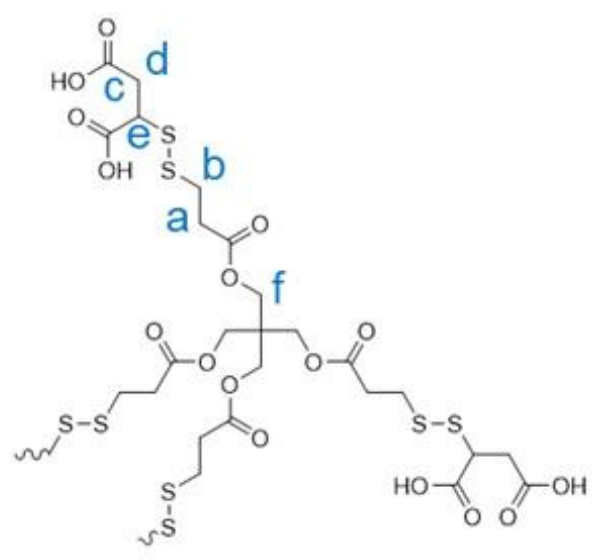

polyMSA 2:1

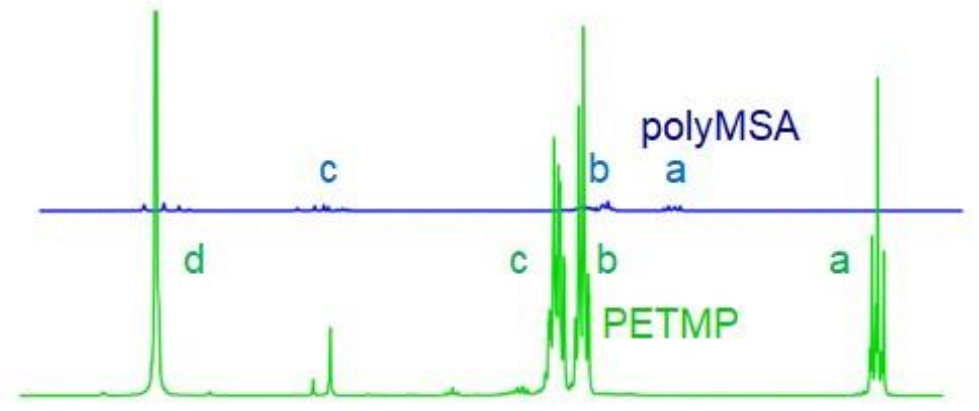

b a

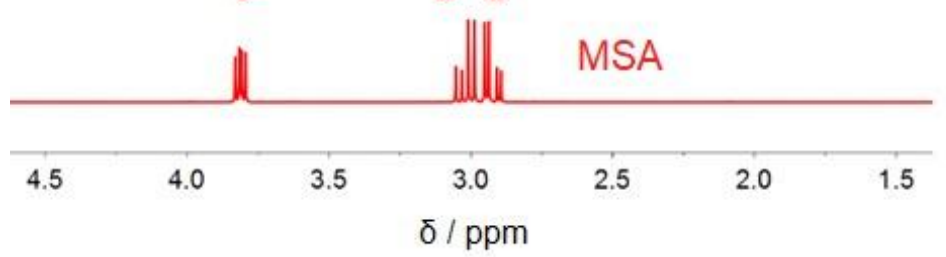

Figure S3. ${ }^{1} \mathrm{H}-\mathrm{NMR}$ spectra of MSA, PETMP and polyMSA with spectra assignment. MSA measured in $\mathrm{D}_{2} \mathrm{O}$, PETMP measured in d8-THF and polyMSA measured in $\mathrm{D}_{2} \mathrm{O}$. 

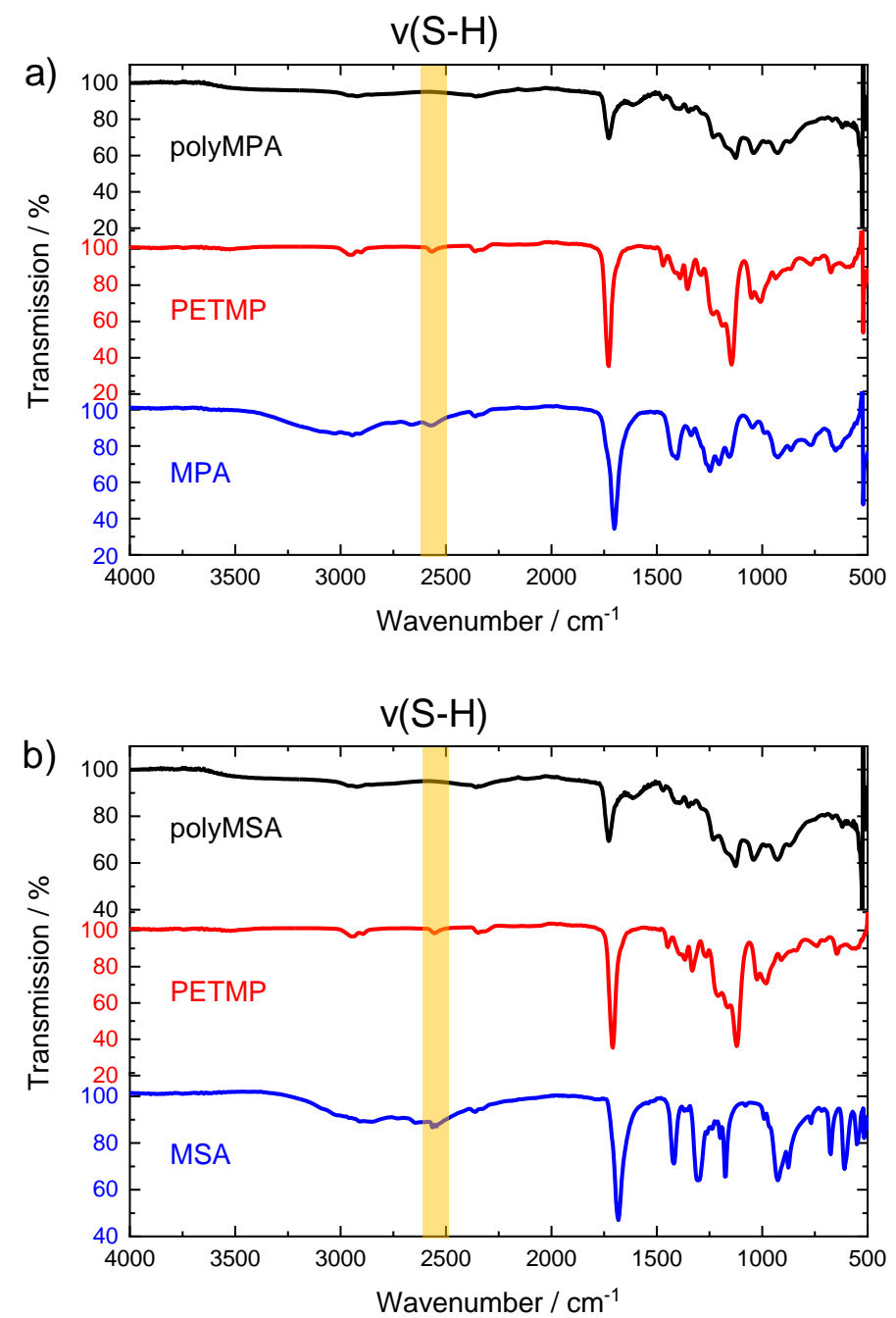

Figure S4. FT-IR spectroscopy of disulfide polymers and their individual building blocks with thiol region highlighted in yellow. a) FT-IR spectrum of polyMPA and its building blocks MPA and PETMP, b) polyMSA and its building blocks MSA and PETMP.

a)

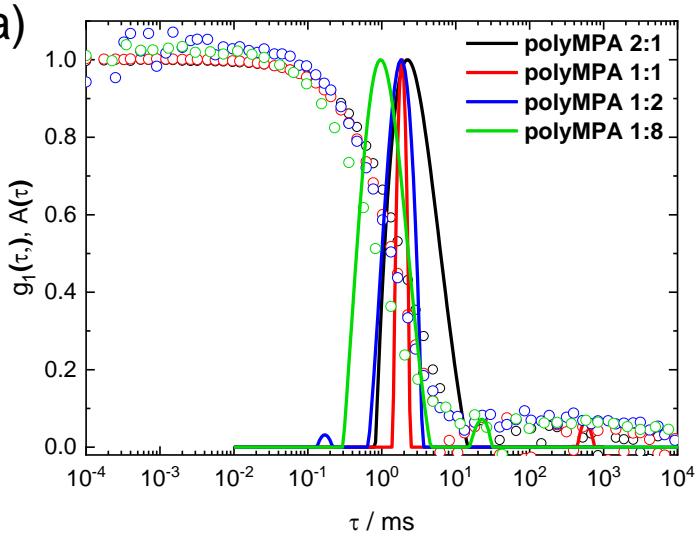

b)

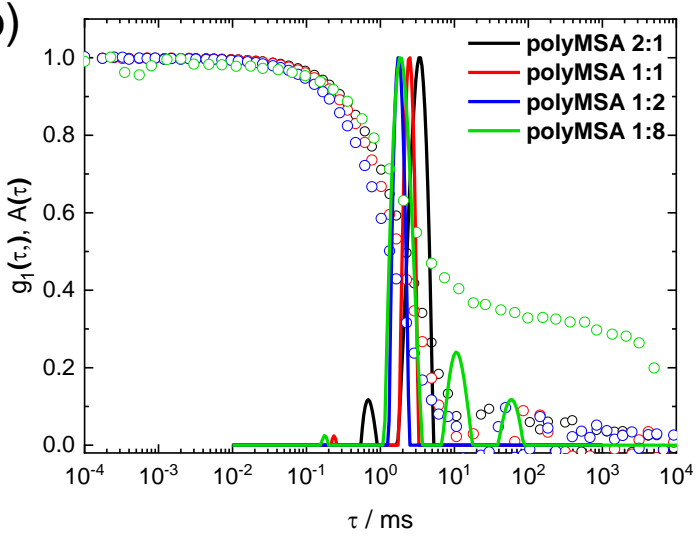

Figure S5. Dynamic Light Scattering of disulfide polymers obtained at varying PETMP:MPA (a) and PETMP:MSA ratios (b): Autocorrelation function of the electric field $\mathrm{g}_{1}(\mathrm{~T})$ (circles) and distribution function of relaxation times $\mathrm{A}(\mathrm{T})$ (lines) (at a scattering angle $\theta=90$ ). 
a)
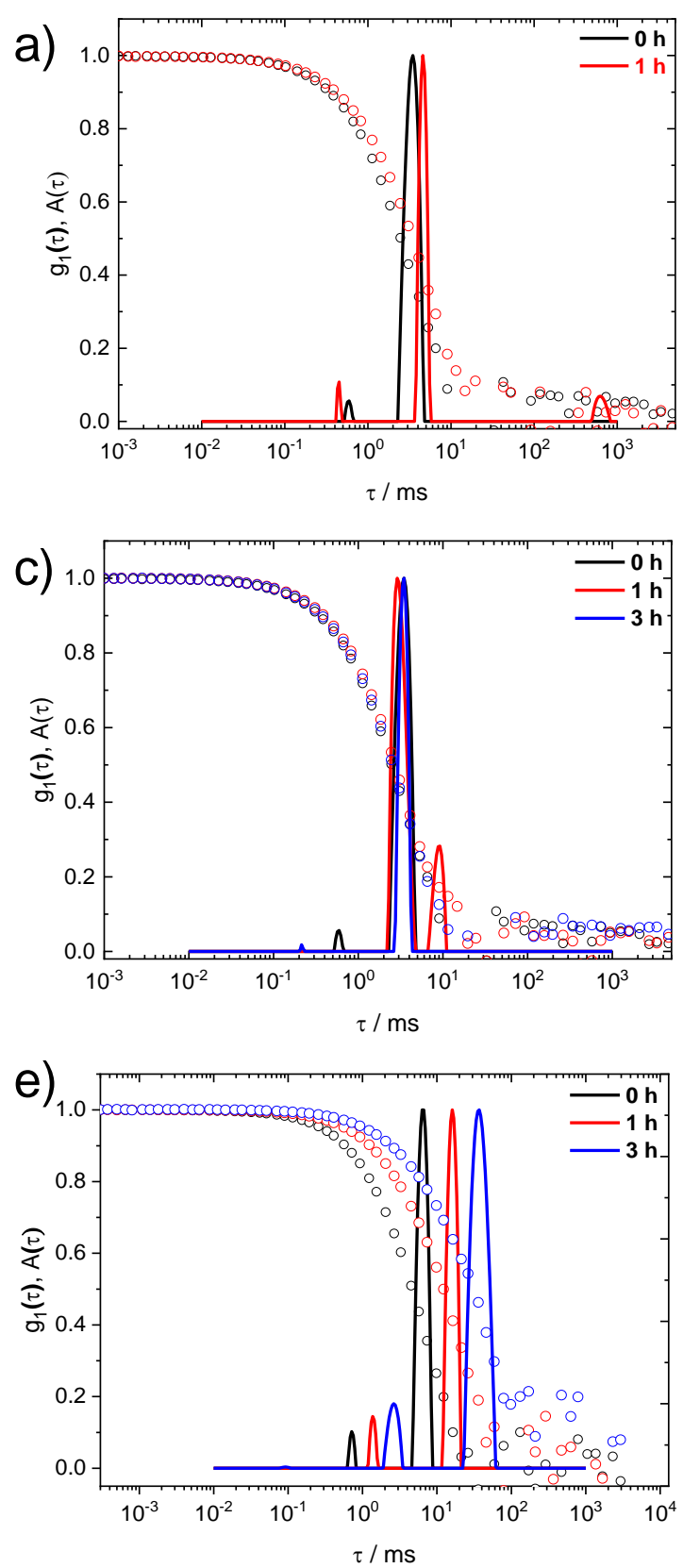
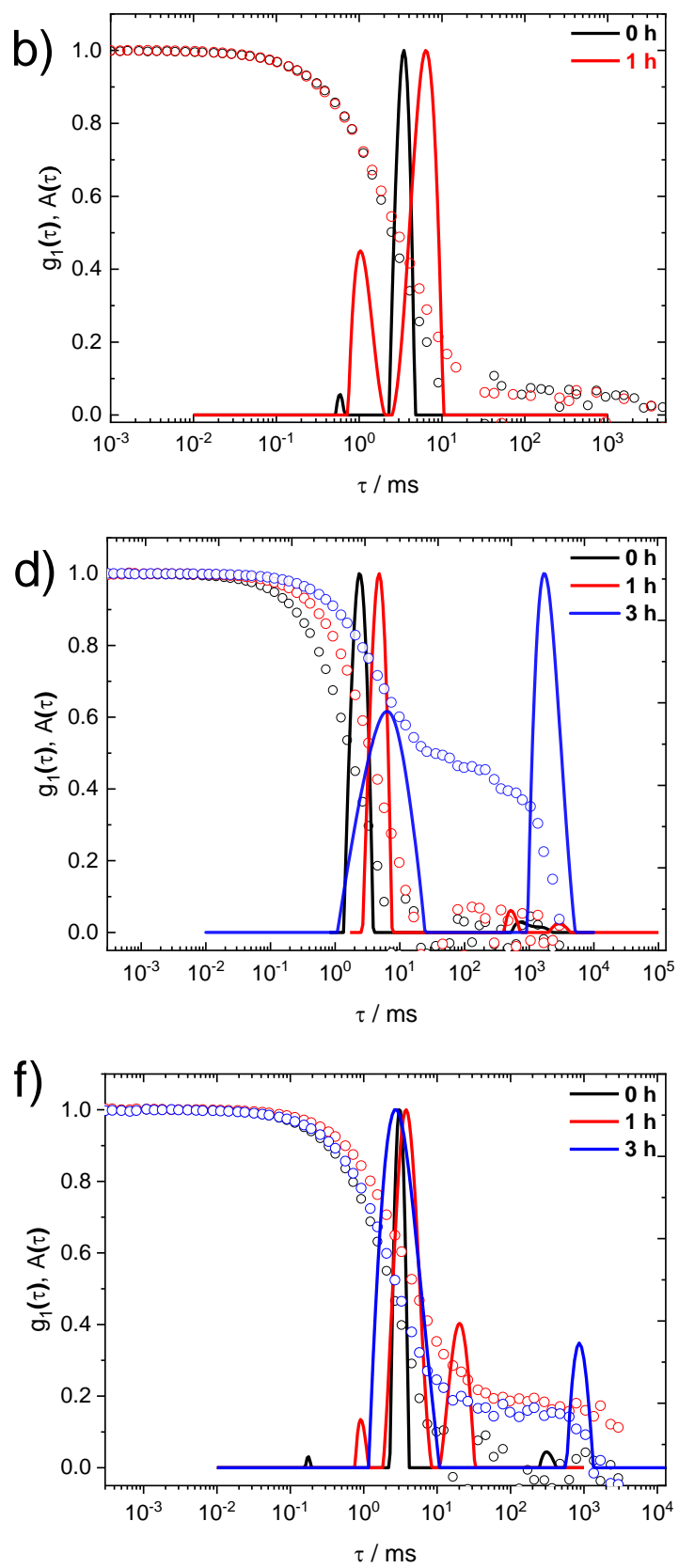

Figure S6. Dynamic light scattering of polyMPA 2:1 triggered and respective control groups. Autocorrelation function of the electric field (circles) $g_{1}(\mathrm{~T})$ and distribution function $\mathrm{A}(\mathrm{T})$ (line) of relaxation times (lines) (at a scattering angle $\theta=90^{\circ}$ ). Stimuli: a) UV-light control, b) UV-light in presence of DTBA, c) ultrasound without DTBA, d) ultrasound in presence of DTBA, e) MPA at $\mathrm{pH}=7$, f) DTBA at $\mathrm{pH}=7$. 

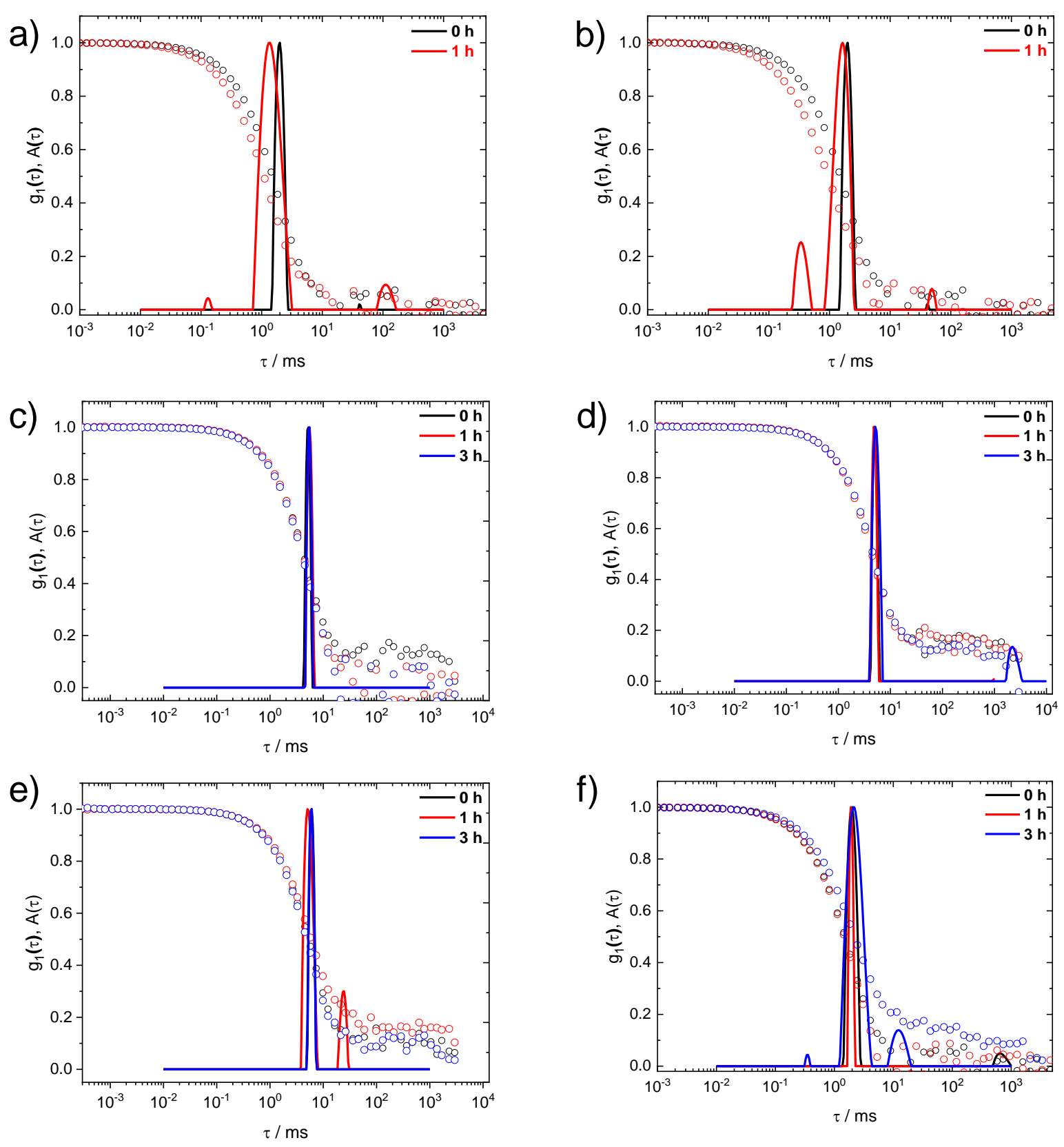

Figure S7. Dynamic light scattering of polyMSA 2:1 triggered and respective control groups. Autocorrelation function of the electric field (circles) $g_{1}(\mathrm{~T})$ and distribution function $\mathrm{A}(\mathrm{T})$ (line) of relaxation times (lines) (at a scattering angle $\theta=90^{\circ}$ ). Stimuli: a) UV-light control, b) UV-light in presence of DTBA, c) ultrasound without DTBA, d) ultrasound in presence of DTBA, e) MSA at $\mathrm{pH}=7, \mathrm{f}) \mathrm{DTBA}$ at $\mathrm{pH}=7$. 
a)

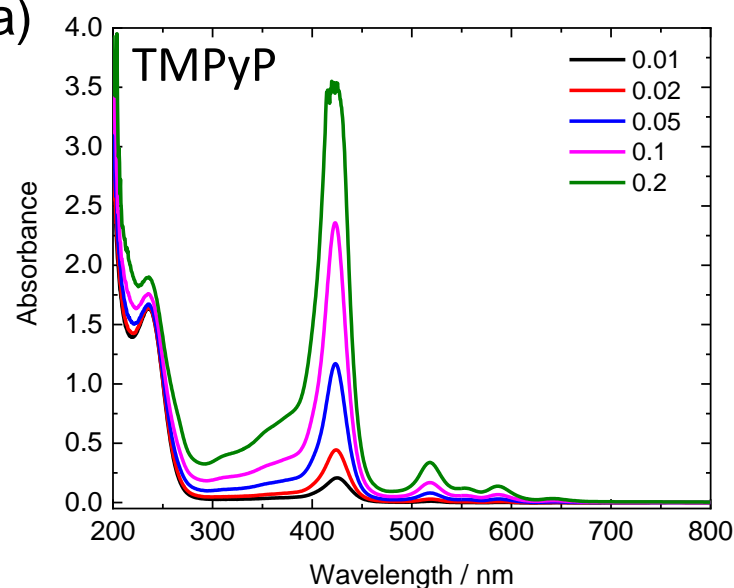

c)

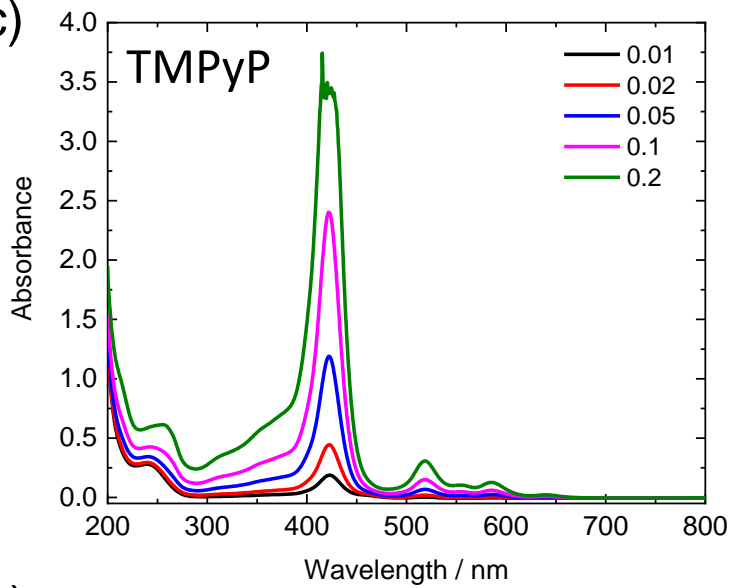

e)

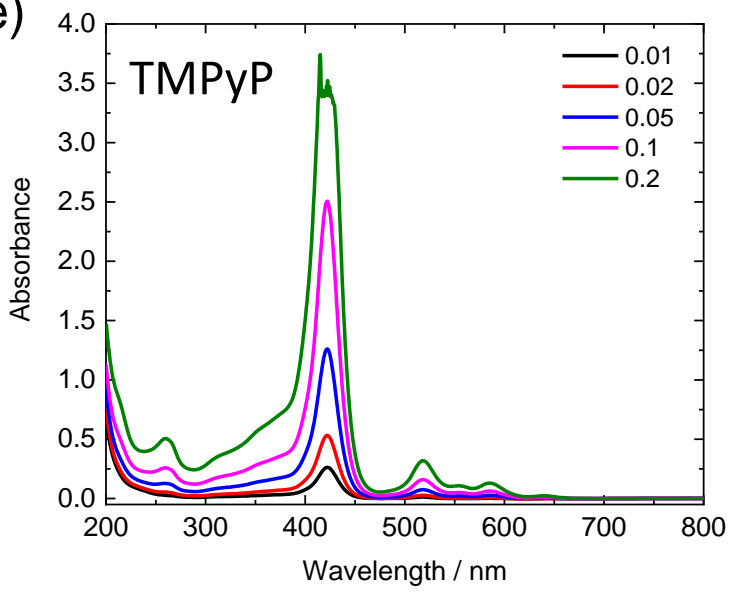

b)

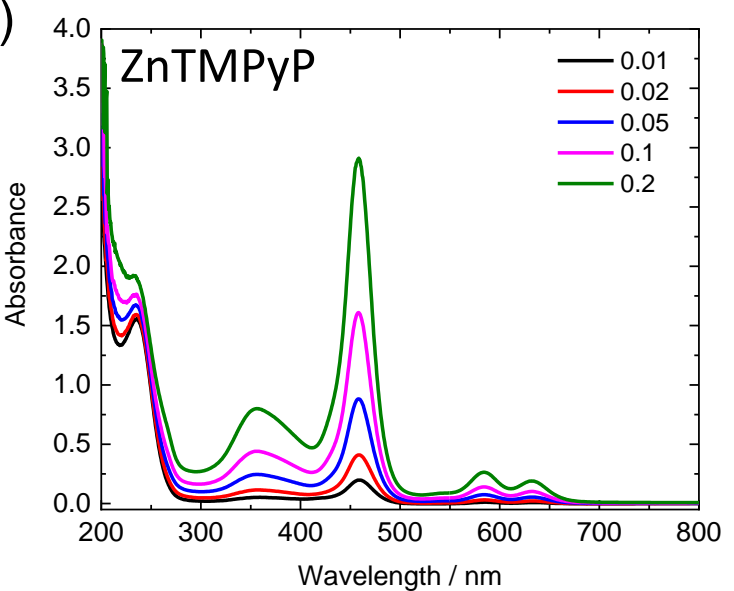

d)

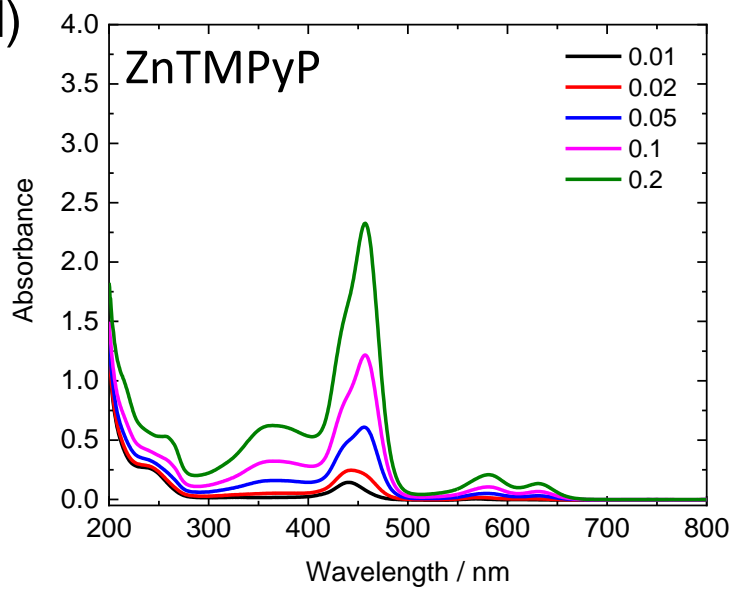

f)

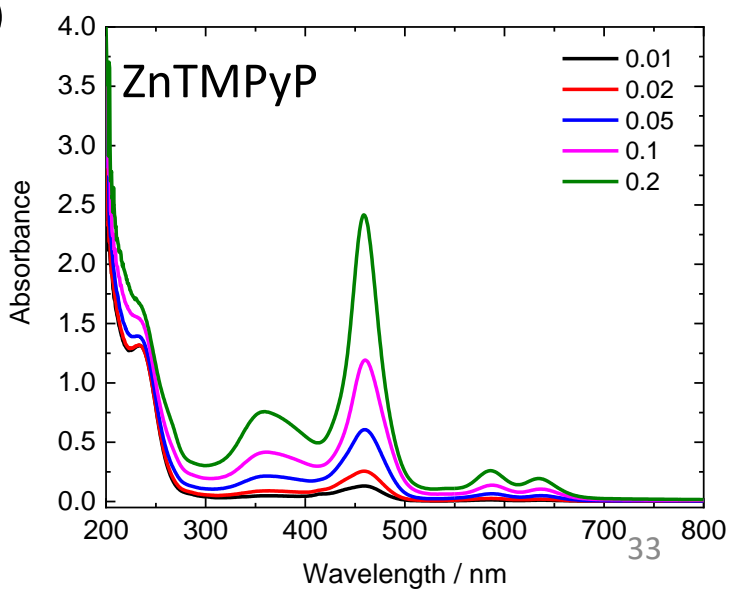

Figure S8. UV-vis spectroscopy of thiols interacting with metalated ZnTMPyP and unmetalated TMPyP in dependence on the loading ratio I. a) PETMP+MPA 2:1 ratio + TMPyP, b) PETMP+MPA 2:1 ratio + ZnTMPyP, c) MSA + TMPyP, b) MSA + ZnTMPyP, e) PETMP+MSA 2:1 ratio + TMPyP, f) PETMP+MSA 2:1 ratio + ZnTMPyP.

Note: The PETMP + MPA as well as the PETMP + MSA samples are unoxidized. In case of the ZnTMPyP spectra, the broad band from $\lambda=300 \mathrm{~nm}$ to $\lambda=400 \mathrm{~nm}$ evolving can be attributed to the interaction of thiols with the metal center, as it is neither present in the polymer samples as well as in the non-metalated samples. 
a)

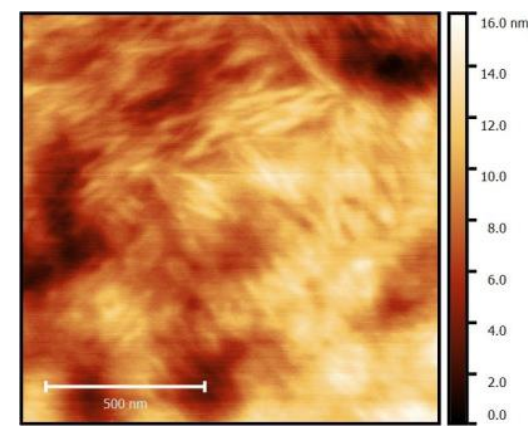

c)

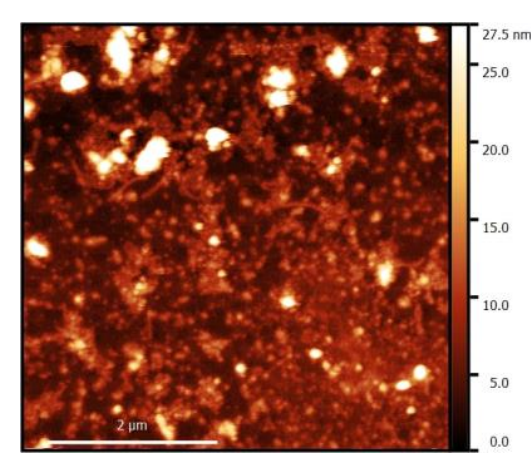

b)

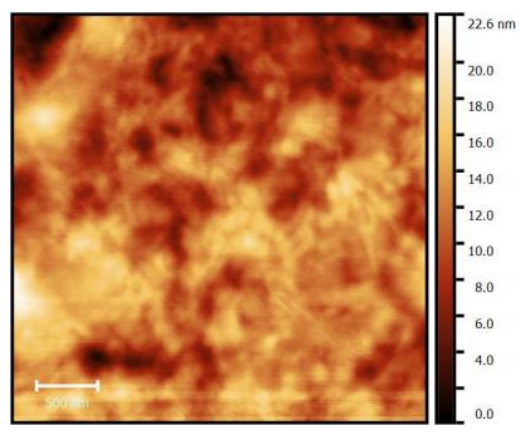

d)

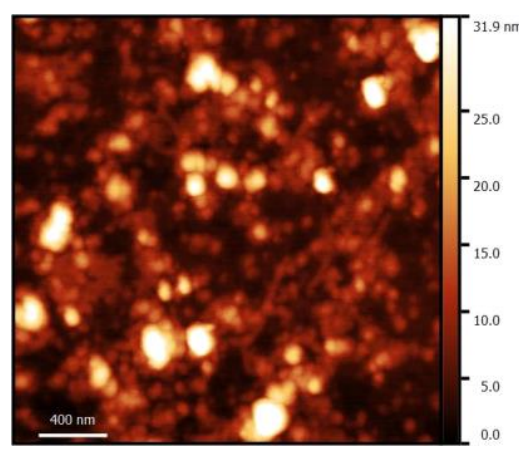

Figure S9. AFM of polyMPA 2:1 and polyMSA 2:1 assembled with ZnTMPyP at a loading ratio I = 0.01. a, b) AFM of polyMPA 2:1 porphyrin assemblies exhibiting fine needles; $c$,d) polyMSA 2:1 porphyrin assemblies representing more spherical particles.

a)

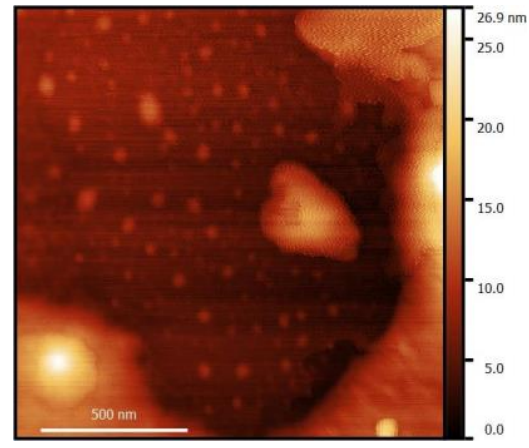

c)

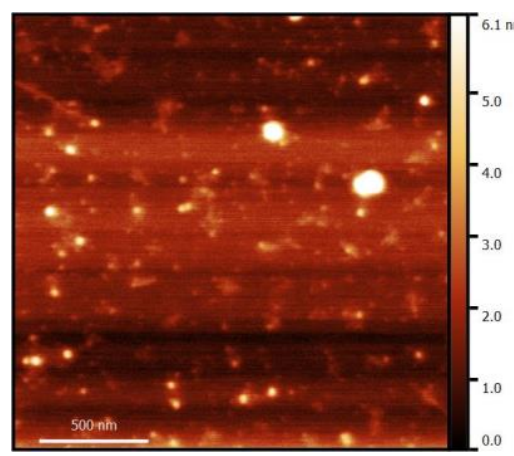

b)

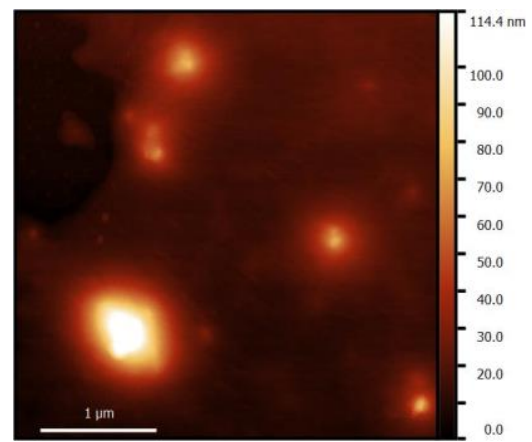

d)

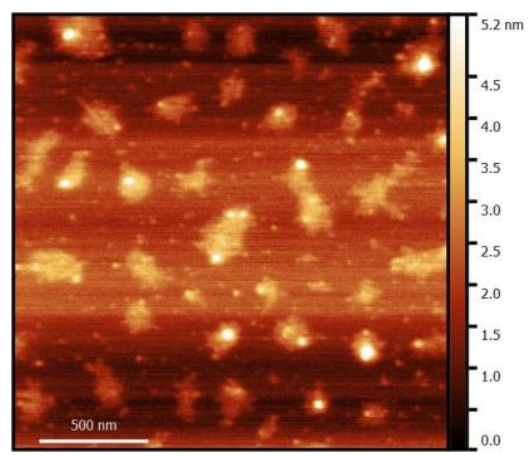

Figure S10. AFM of polyMPA 2:1 assembled with ZnTMPyP at a loading ratio I $=0.01$, triggered with a), b) ultrasound, c), d) UV-light 

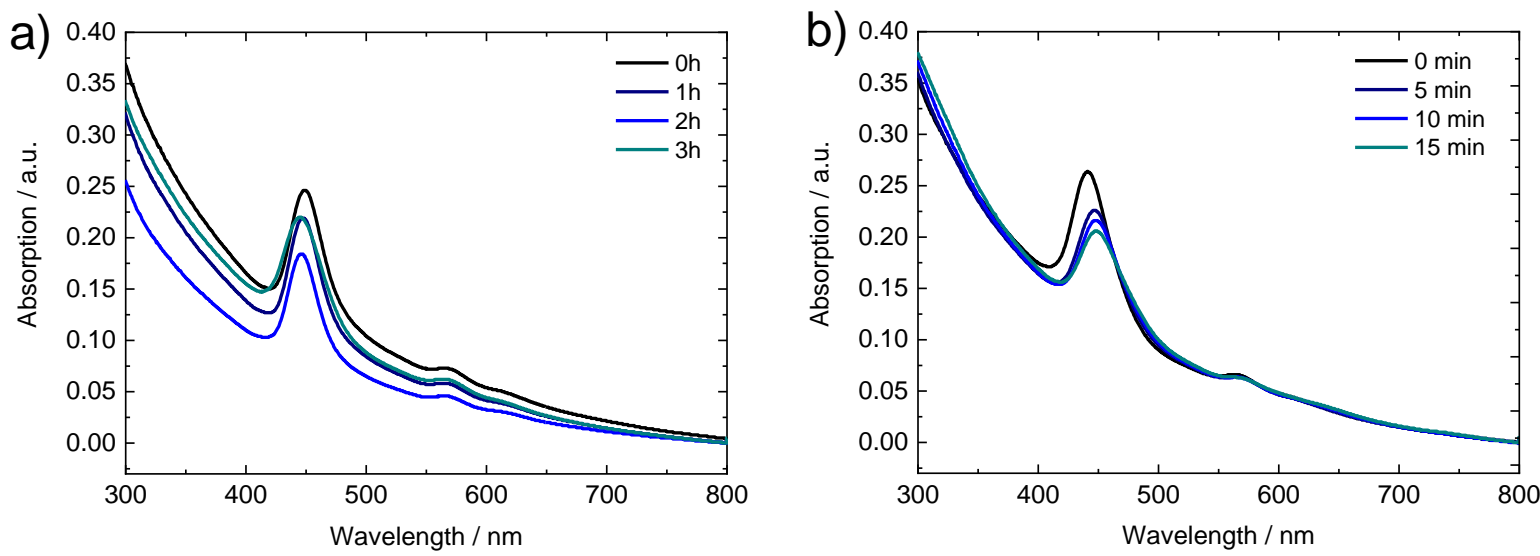

Figure S11. UV-vis spectroscopy of polyMPA 2:1 ZnTMPyP assemblies at loading ratio I $=0.01$ triggered with a) DTBA (control without application of ultrasound) and b) UV light (without DTBA in solution).

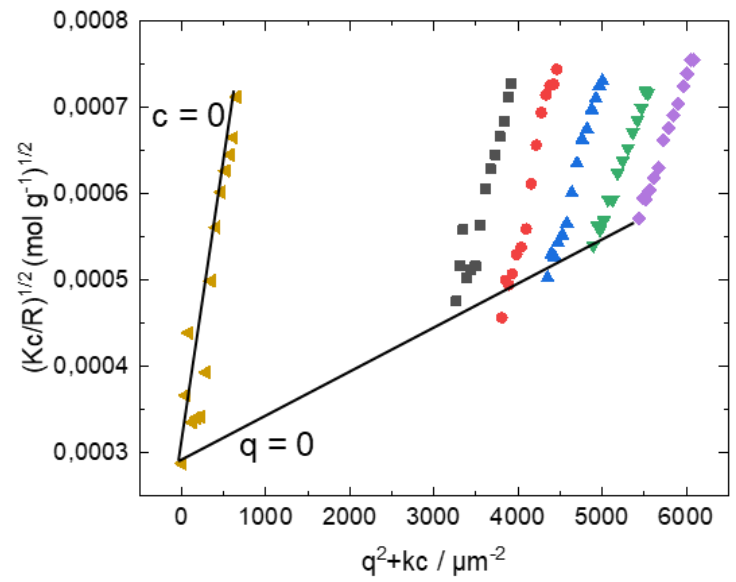

Figure S12. Static light scattering for molar mass determination: Berry-Plot of polyMSA 2:1 synthesized at a concentration of $c(R-S H)=10^{-2} \mathrm{~mol} \mathrm{~L}^{-1}$. c(samples): $0.066 \mathrm{~g} \mathrm{~L}^{-1}$ (gray), $0.077 \mathrm{~g} \mathrm{~L}^{-1}$ (red), $0.088 \mathrm{~g} \mathrm{~L}^{-1}$ (blue), $0.099 \mathrm{~g}$ $\mathrm{L}^{-1}$ (green), $0.110 \mathrm{~g} \mathrm{~L}^{-1}$ (purple) and extrapolated sample against $\mathrm{C}=0 \mathrm{~g} \mathrm{~L}^{-1}$ (orange). 


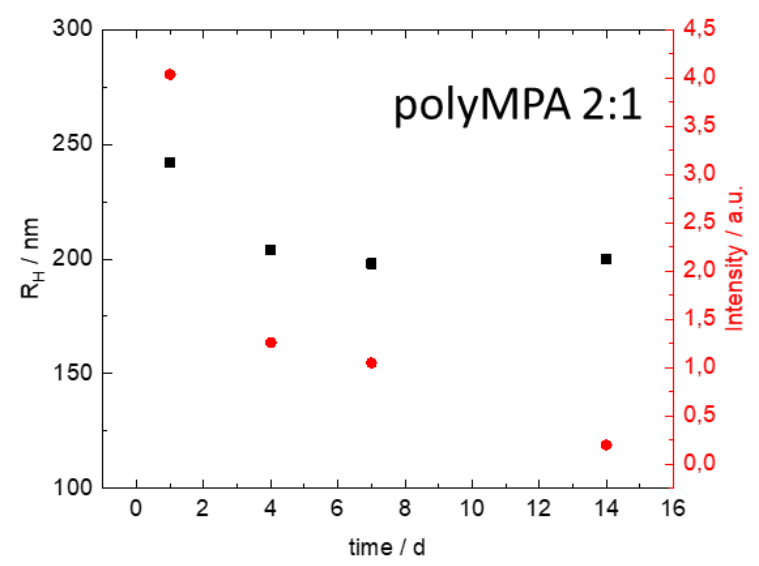

Figure S13. Stability of polyMPA over a duration of two weeks derived from $\mathrm{RH}_{\mathrm{H}}$ and scattering intensity of the supernatant of the solution. Sedimentation of the samples leads to decreasing intensities.

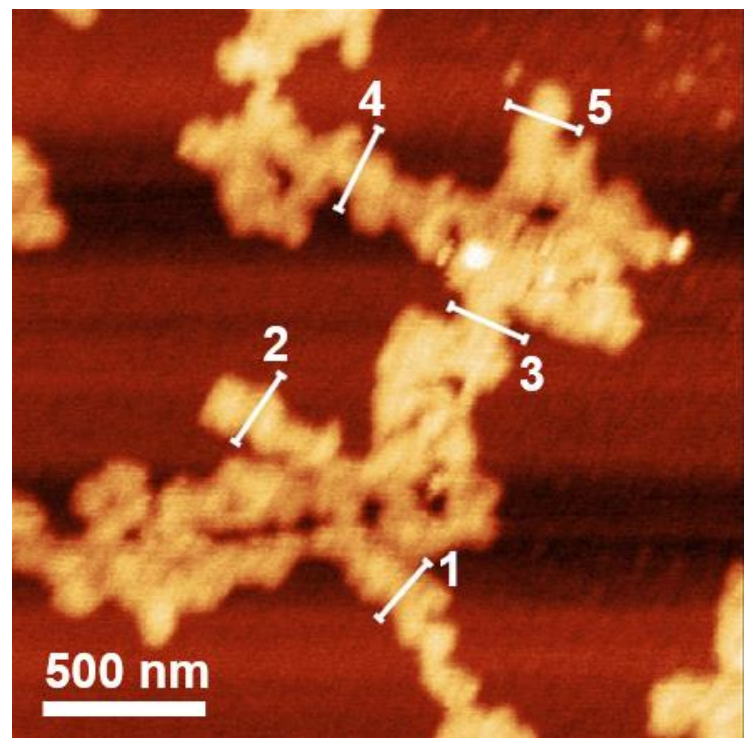

Figure S14. AFM analysis of polyMPA 2:1: higher magnification used for the height profile in Figure $3 \mathrm{~b}$. 